\title{
Aproximación de la dinámica poblacional de los microorganismos en diferentes sustratos empleados en el cultivo de rosa (Rosa spp. var. Charlotte) en la Sabana de Bogotá
}

\section{Overview of the population dynamics of microorganisms in different substrates used in rose (Rosa spp. var. Charlotte) cultivation on the Bogota Plateau}

MILENA ALFONSO 1

ALEJANDRO COCA ${ }^{1}$

WILLIAM RAMÍREZ

LILIANA HOYOS-CARVAJAL',2

Cultivo de rosa var. Charlotte bajo invernadero en la Sabana de Bogotá.

Foto: V.J. Flórez

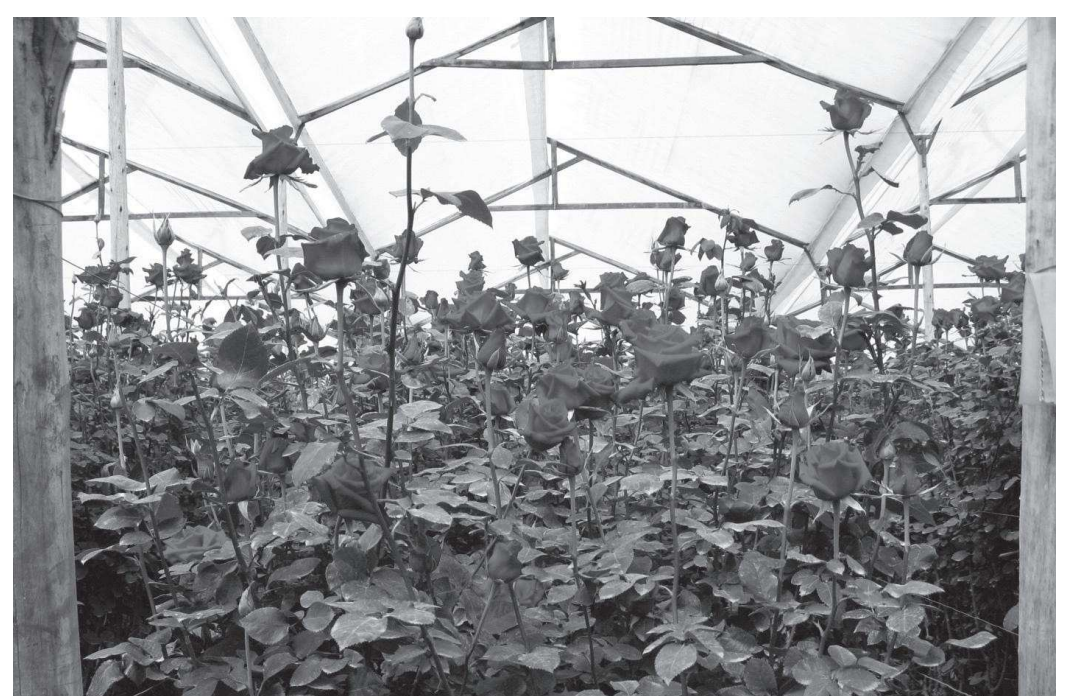

\section{RESUMEN}

La identificación y estudio de la dinámica poblacional de los microorganismos permite reconocer y determinar sus cambios físicos o estructurales en una unidad de tiempo y espacio. En el caso de la rosa, son pocos los estudios que detallan esta información. Esta investigación evaluó la dinámica poblacional de los microorganismos (hongos y bacterias) en un cultivo experimental de rosa var. Charlotte ya establecido en la Sabana de Bogotá y dispuesto en cinco sustratos (suelo 100\%, cascarilla de arroz 100\%, mezcla de cascarilla de arroz y fibra de coco $65: 35 \%$ (v/v), mezcla de cascarilla de arroz y fibra de coco $35: 65 \%$ (v/v) y fibra de coco $100 \%$ ) en un sistema con recircularización de nutrientes. Se realizaron dos muestreos con un mes de diferencia y las muestras de los sustratos fueron analizadas en el laboratorio, donde se caracterizaron e identificaron los microorganismos presentes. Se hicieron conteos a las 24 y 48 horas después de siembra en tres medios de cultivo (PDA, AN y $\mathrm{D} 1 \mathrm{M})$. Los resultados de la dinámica poblacional entre los dos muestreos determinaron una mayor actividad de hongos y bacterias en el segundo muestreo, indicando que los microorganismos cambian su actividad y en algunos casos la presencia o ausencia de ciertos géneros teniendo como variable el tiempo, siendo en el caso de los hongos los géneros Mucor y Cladosporium, los que mayor ocurrencia tuvieron en todos los tratamientos.

1 Grupo de Investigación en Fitopatología, Departamento de Agronomía, Facultad de Agronomía, Universidad Nacional de Colombia, Bogotá (Colombia).

2 Autor para correspondencia.limhoyosca@unal.edu.co 


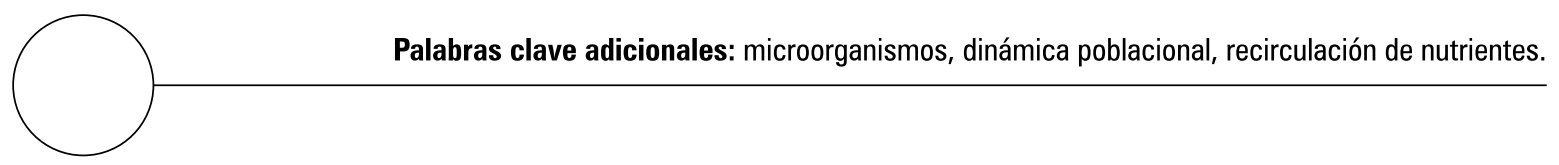

ABSTRACT

Information on the distribution and population dynamics of microorganisms facilitates recognition of physical or structural changes that may occur in both time and space. In the case of the rose, a few studies are available that provide such information. In this study, the population dynamics of microorganisms (fungi and bacteria) associated with the established experimental rose variety Charlotte was evaluated on the Bogotá Plateau in five substrates: $100 \%$ soil, 100\% rice husks, a $65: 35 \%(\mathrm{v} / \mathrm{v})$ mixture of rice husks and coconut fiber, a $35: 65 \%(\mathrm{v} / \mathrm{v})$ mixture of rice husks and coconut fiber, and 100\% coconut fiber, all in a system with $100 \%$ nutrient recirculation. Samples were taken on two dates with a month between the samplings and the microorganisms were characterized and identified in the laboratory. Samples were plated in three culture media: PDA, AN and D1M and counted after 24 and 48 hours. Greater incidence of both fungi and bacteria from the second sampling indicated that the microorganisms increased activity over time, with the presence or absence of certain genera also varying over time. Among the fungi, the genera Mucor and Cladosporium had the highest incidence over all treatments.

Additional keywords: microorganisms, population dynamics, nutrient recircularization.

El suelo es un ambiente complejo y dinámico en el cual la actividad biológica está en mayor medida dominada por la actividad de los microorganismos (Gomes et al., 2003). La diversidad microbiana es fundamental para el funcionamiento del ecosistema, debido a la diversidad de procesos como la descomposición, ciclaje de nutrientes, agregación del suelo, antagonismos y patogenicidad (Dubey et al., 2006). En el caso de la agricultura y campos afines, un estudio del papel de los microorganismos del sistema suelo-planta, y con mayor énfasis en la rizosfera, permite generar un mayor uso sostenible del mismo, encaminado a unos mayores rendimientos de los cultivos, los cuales estén relacionados a un manejo adecuado que favorezca el medioambiente.

El tipo de suelo ejerce un fuerte efecto sobre las comunidades de la rizosfera, siendo principalmente sus diferencias en pH, aireación y características físico-químicas las que generan comunidades de microorganismosdefinidasyespacialmentevariables. Asimismo, la disponibilidad de nutrientes minerales, como el nitrógeno, fosforo o hierro y la cantidad de carbono en el suelo pueden afectar también el número de microorganismos en la rizosfera y cambiar la composición de la comunidad de los mismos (Marschner et al., 2001). Por otra parte, los microorganismos asociados con la raíces de las plantas son importantes en la nutrición, promoción del crecimiento e interacciones por patogenicidad (Marschner et al., 2001). En algunos casos, la composición de la comunidad de la rizosfera puede estar influenciada por el genotipo de la planta, aunque existen excepciones (Cattelan et al., 1998). Los efectos de las especies de plantas son probablemente debidos a las diferencias en los componentes de las células y 
exudados de la raíz, los cuales pueden también variar con la zona radicular, edad de la planta, cantidad de nitrógeno e infección por hongos micorrízicos (Marschner et al., 2001).

Existen reportes de investigaciones sobre comunidades de microorganismos de la rizosfera interactuando en diferentes clases de suelos y con varias especies de plantas. En algunos casos, el efecto del tipo de suelo sobre los microorganismos fue mayor que el de las plantas (Buyer et al., 1999; Damastri et al., 1999) y en contraste de acuerdo con estudios realizados por Grayston et al. (1998) y Miethling et al. (2000), las especies de plantas tuvieron un efecto mayor sobre la composición de la comunidad de la rizosfera que el tipo de suelo (Marschner et al., 2001).

El cultivo de la rosa, que en la actualidad ocupa el 36,5\% del área total sembrada en Colombia y que forma parte del $48 \%$ de la exportación de flor cortada del país (Asocolflores, 2007), es afectado por varias enfermedades causadas por patógenos de suelo, los cuales producen pérdidas y sobrecostos en la producción cada año (Asocolflores, 2003). Los floricultores, ante esta problemática, han optado por emplear como alternativa al suelo otros medios de soporte, como cascarilla de arroz quemada, fibra de coco o mezcla de éstas, con el fin de disminuir la incidencia de enfermedades. Estas opciones en la mayoría de los casos se han empleado sin el sistema de recircularización de nutrientes (Pizano, 2000). Sin embargo, esta técnica tiene grandes ventajas, ya que permite que la solución madre sea desinfectada por métodos físicos o químicos (filtración, calefacción, cloración entre otros) y algunos agentes biológicos (Steijl et al., 1999; Chave et al., 2008).

Actualmente son escasos los reportes de estudios que indiquen cómo es el comportamiento microbiológico en los sustratos empleados bajo el sistema de recirculación de nutrientes en cultivos de rosa en la Sabana de Bogotá. Dado lo anterior, el Grupo de Investigación de Fitopatología de la Facultad de Agronomía de la Universidad
Nacional de Colombia ha propuesto el siguiente estudio, con el fin de determinar la dinámica poblacional de los microorganismos en los diferentes sustratos empleados de manera comercial en el cultivo de rosa en la Sabana de Bogotá, por medio de aislamientos, caracterizaciones y pruebas bioquímicas.

\section{MATERIALES Y MÉTODOS}

El estudio se realizó en el Centro Multisectorial de Mosquera, Regional de Cundinamarca, en un cultivo tipo comercial de cuatro años de rosa variedad Charlotte, injertadas sobre el patrón 'Natal Briar', el cual estaba sembrado en materas con capacidad de $8 \mathrm{~L}$ y con cinco diferentes sustratos (tabla 1).

\section{Recolección, cuantificación, aislamiento y caracterización de los microorganismos}

Los muestreos se realizaron el 29 de septiembre y el 27 de octubre de 2008, con el fin de observary describir los detalles de la dinámica poblacional de cada uno de los sustratos. Para la obtención de muestras, se tomó una submuestra por matera, recogiendo así una cantidad de sustrato considerable y representativo del mismo. Posteriormente se homogeneizó el material, conformando una muestra final de $500 \mathrm{~g}$ por cada sustrato.

El procesamiento de las muestras se realizó en el Laboratorio de Microbiología de la Facultad de Agronomía de la Universidad Nacional de Colombia, sede Bogotá. Los sustratos se secaron a

Tabla 1. Sustratos usados en el estudio.

\begin{tabular}{|r|l|}
\hline No. & \multicolumn{1}{|c|}{ Tipo de sustrato } \\
\hline 1 & Suelo. \\
\hline 2 & Cascarilla de arroz quemada $100 \%$. \\
\hline 3 & Cascarilla de arroz quemada más fibra de coco $65: 35$. \\
\hline 4 & Cascarilla de arroz quemada más fibra de coco $35: 65$. \\
\hline 5 & Fibra de coco $100 \%$. \\
\hline
\end{tabular}


temperatura ambiente para eliminar el contenido de agua y hacer las disoluciones en seco. Luego, mediante métodos físicos (molido, macerado, tamizado y mezclado) cada material fue homogenizado para garantizar la representatividad de los resultados obtenidos en el análisis. Para realizar el análisis microbiológico, se empleó el método de las diluciones, ya que permite apreciar de manera cualitativa la actividad de las especies aisladas (Agrios, 2005).

Con la ayuda de una pipeta estéril, se tomaron $100 \mu \mathrm{L}$ de la dilución correspondiente $\left(10^{-3}\right.$ para hongos y $10^{-5}$ para bacterias) de cada sustrato y se sirvió en una caja de Petri estéril con un medio de cultivo específico: PDA, agar nutritivo (AN) para hongos y bacterias y (D1M) específico a Agrobacterium tumefaciens. El material sembrado en las cajas se dispuso en una cámara de crecimiento a $22^{\circ} \mathrm{C}$ y se realizó un conteo a las 24 , 48 y 72 h después de incubación, con el fin de observar si existía alguna diferencia significativa en cuanto a la cantidad de hongos y bacterias presentes por tratamiento.

Se llevó un registro fotográfico y se realizó la caracterización macroscópica de los hongos y bacterias, determinando a su vez el porcentaje de frecuencia de acuerdo con los géneros o morfotipos identificados, respectivamente. Para la caracterización del género de hongos, se utilizó la metodología de la impronta y la clave taxonómica de Barnett y Hunter (1998). En el caso de las bacterias, de acuerdo con las que mayor frecuencia presentaban (1 ó 2 morfotipos por tratamiento), se caracterizaron macroscópica y microscópica, adicionalmente se les realizó la prueba de tinción de Gram.

\section{Análisis estadístico}

El análisis estadístico del estudio para la evaluación en laboratorio, específicamente la cuantificación según el caso de bacterias y hongos a las 24 y $48 \mathrm{~h}$ después de siembra (hds), estuvo basado en un diseño completamente al azar, con cinco tratamientos (tipo de sustrato) y seis repeticiones por medio para un total de 90 cajas por muestreo. Los datos se sometieron a un análisis de varianza y una prueba de rango múltiple de Tukey $(P \leq 0,05)$, utilizando como software de soporte, SAS versión $9.1{ }^{\circledR}$.

\section{RESULTADOS Y DISCUSIÓN}

\section{Cuantificación de los microorganismos}

En los dos muestreos realizados se evidenció que la dinámica poblacional en el cultivo de rosa bajo los distintos sustratos es fluctuante, teniendo como variable el tiempo (figura $1 \mathrm{~A}$ y figura 1B). Se comprobó en este caso que las bacterias, debido a su cantidad en los conteos, tienen una mayor actividad en todos los sustratos evaluados respecto a la población de hongos. Según Olalde y Aguilera (1998), las bacterias representan entre el $25 \%$ y $30 \%$ de la biomasa microbiana del suelo, comportándose como los organismos más numerosos del suelo (entre 106 y 107 bacterias/g de suelo), mientras que los hongos, dado su mayor tamaño y presentando menor abundancia, evidencian la biomasa más significativa. En complemento, Blaine (1992) señala que las bacterias son numerosas por su pequeño tamaño, pero los hongos son probablemente de igual o mayor importancia en muchos suelos por su biomasa significativa, asociación íntima con los sistemas radiculares y competencia saprofita con grandes detritus físicos y componentes estructurales complejos.

En el caso de los hongos, se observó en el segundo muestreo un cambio evidente y pronunciado en cuanto a su población a las 48 h después de siembra, siendo los tratamientos de cascarilla de arroz $100 \%$ y fibra de coco $100 \%$ significativamente diferentes $(P \leq 0,05)$ y en mayor cantidad en cuanto a ufc/g de hongos suelo respecto a los demás tratamientos (figura 1A). Este comportamiento puede estar dado por intervención de factores ambientales o condiciones físico-químicas 

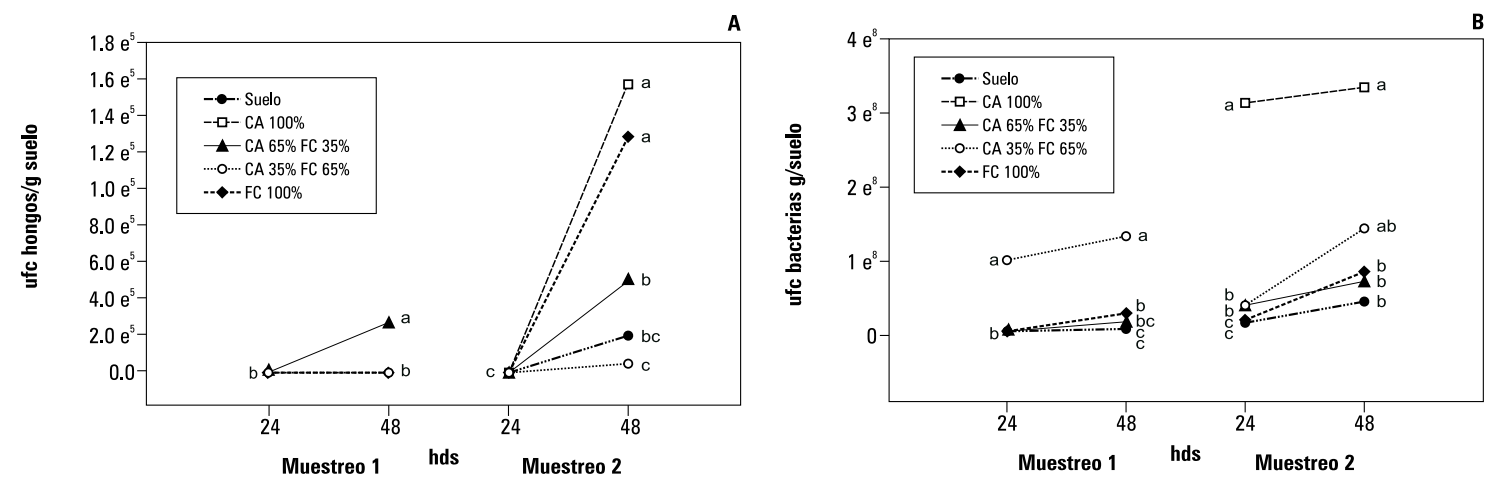

Figura 1. Cuantificación de hongos (A) y bacterias (B) a las 24 y 48 h después de siembra (hds) en materas de rosa con recirculación de nutrientes en Mosquera, Colombia. Promedios con letras distintas indican diferencias significativas según la prueba de Tukey $(P \leq 0,05)$.

favorables ( $\mathrm{pH}$, porosidad, fertilización, entre otros) de estos sustratos para un desarrollo más acelerado de las colonias de hongos.

Las bacterias presentaron una tendencia similar, pero menos marcada, respecto al crecimiento de los hongos, indicando quizás una mayor estabilidad en cuanto a un cambio gradual en el tiempo de las condiciones del sustrato (figura 1B). Se observa en este caso que en el medio de mezcla de cascarilla de arroz 35\% y fibra de coco $65 \%$ presentan cierta cantidad mayor de bacterias tanto en el primer como en el segundo muestreo, siendo esto una posible indicación de una mayor actividad bacteriana en este sustrato. El notable crecimiento de número de bacterias en el sustrato de cascarilla de arroz $100 \%$ en el muestreo 2 puede deberse en mayor medida a una condición bastante favorable (ambiente o sustrato) que genera una mayor actividad de estos microorganismos en el tratamiento.

\section{Caracterización e identificación de los hongos}

Típicamente, los hongos edáficos son más abundantes en la proximidad de la superficie que en el subsuelo y lo son, asimismo, en los suelos ligeros y bien aireados que en los pesados (Wild, 1989). Las características microscópicas permitieron identificar un total de siete géneros de hongos y no se logró identificar un género con características de micelio septado y hialino, debido a la carencia de una estructura reproductiva o micelar propia para su clasificación (figura 3). En el primer muestreo, los géneros Mucor sp. y Cladosporium sp. resultaron ser los hongos con mayor presencia y porcentaje de ocurrencia en todos los sustratos evaluados (tabla 2). Esta alta frecuencia se relaciona posiblemente a una alta capacidad competitiva y colonizadora de ambos géneros. En la parte fitopatológica, las especies del género Mucor se caracterizan por un micelio bastante grueso y resultan ser solamente relevantes en la poscosecha de los alimentos, en la cual pueden generarse pudriciones del material vegetal cosechado, generando grandes perdidas, teniendo en cuenta que las especies tienden a ser muy resistentes a los fungicidas (Smith, 1992).

La mayoría de las especies de Cladosporium sp. son saprófitos y crecen sobre una gran variedad de sustratos. Su caracterización microscópica se baso en la presencia de conidióforos oscuros con varias ramas cerca de la porción superior o media, 


\begin{tabular}{|c|c|c|c|c|c|}
\hline \multirow{2}{*}{ Género } & \multicolumn{5}{|c|}{ Tratamiento } \\
\hline & Suelo & CA $100 \%$ & CA $65 \%$ FC $35 \%$ & CA $35 \%$ y FC $65 \%$ & FC $100 \%$ \\
\hline Cladosporium sp. & - & $+(f=69,3 \%)$ & $+(f=26,7 \%)$ & $+(f=50 \%)$ & - \\
\hline Mucor sp. & - & $+(f=4,0 \%)$ & $+(f=66,7 \%)$ & $+(f=6,2 \%)$ & $+(f=100 \%)$ \\
\hline Papulaspora sp. & - & $+(f=26,7 \%)$ & - & - & - \\
\hline Penicillium sp. & - & - & - & $+(f=43,8 \%)$ & - \\
\hline Pythium sp. & $+(f=55,6 \%)$ & - & - & - & - \\
\hline Rhizopus sp. & - & - & $+(f=6,6 \%)$ & - & - \\
\hline Trichoderma sp. & $+(f=33,3 \%)$ & - & - & - & - \\
\hline Sin definir septado hialino & $+(f=11,1 \%)$ & - & - & - & - \\
\hline
\end{tabular}

$\mathrm{f}=$ porcentaje de ocurrencia a las 120 hds.

CA, cascarilla de arroz; FC, fibra de coco.

agrupados o simples, con conidias oscuras de una a dos celulas, variables en forma y tamaño, ovoide a cilíndrico e irregular, las cuales concuerdan con lo descrito por Barnett y Hunter (1998).

En cuanto a otras identificaciones, se destaca la presencia de Pythium sp. y Trichoderma sp. En el primer caso, resulta relevante por su efecto patogénico y oportunista en el establecimiento de plántulas en semilleros (Agrios, 2005) y en el segundo caso como un potencial colonizador de superficies y medios y en adición antagonista de otros hongos (Ezziyyani et al., 2004). Pythium coloniza materia orgánica fresca alcanzando altos niveles de inóculo en 24-48 h; sin embargo, es un mal competidor con otros hongos y bacterias. En algunos casos, los suelos forestales han resultado ser supresivos a las especies patogénicas de Pythium debido a competencia, en particular con Mucorales, de forma que Pythium está aparentemente ausente (Smith, 1992).

En menor medida, se encontraron los géneros de Rhizopus sp. y Papulaspora sp., siendo el primero un Mucoral que presenta especies que resultan importantes debido a los efectos negativos (podredumbres severas) que pueden generar en la producción de hortalizas y frutas (Smith, 1992). En el caso del segundo organismo, es poco lo que se discute en la literatura, pero entre sus características microscópicas están esporas asexuales carentes, micelio claro y producción de agrupaciones compactas de pequeñas células o bulbilos, los cuales parecieran esclerotizados y sirven para reproducir el hongo (Barnett y Hunter, 1998).

En el segundo muestreo se identificaron cuatro géneros de hongos y uno sin identificar, el cual coincidió con las características hialinoseptadas del hongo sin clasificación del primer muestreo (tabla 3). Prevalecieron nuevamente Cladosporium sp. y Mucor sp., ratificando su capacidad competitiva y presencia característica de los sustratos utilizados en el cultivo de rosa. Por otra parte, se determinó en mayor frecuencia, respecto al primer muestreo, la presencia de $\mathrm{Pe}$ nicillium sp. en los sustratos de cascarilla de arroz más fibra de coco en proporción 65:35 y 35:65 y en fibra de coco $100 \%$.

En caso contrario al primer muestreo, el género Mucor sp. en el suelo (tratamiento 1), indicando como se nombró anteriormente una posible competencia en el medio PDA. Respecto a la pre- 

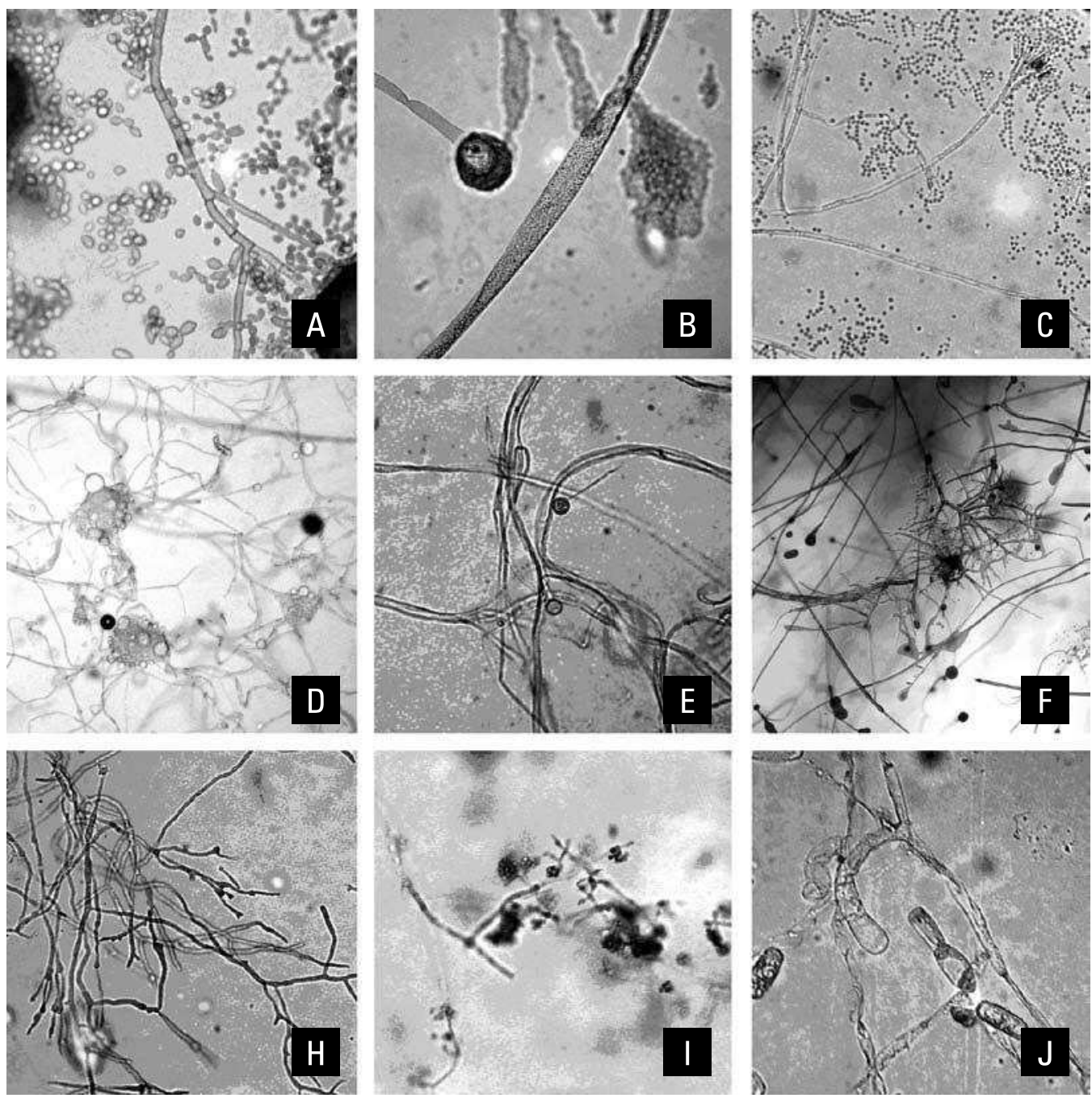

Figura 2. Fotografías microscópicas $(40 \mathrm{X})$ de las estructuras características de los géneros de los hongos identificados en todos los sustratos de rosa en materas con recirculación de nutrientes en Mosquera, Colombia. Cladosporium sp. (A), Mucor sp. (B), Penicillium sp. (C), Papulaspora sp. (D), Pythium sp. (E), Rhizopus sp. (F), sin identificar-septado-hialino (G), Trichoderma sp. (H) y conidias de Sphaerotheca pannosa (I).

sencia de Trichoderma en el suelo en ambos muestreos, puede indicar una posible restricción de crecimiento y desarrollo de otros hongos, en lo posible fitopatógenos (Fernández-Larrea, 2001). Esto sería óptimo desde un punto de vista ambiental, ya que por acciones naturales se reduciría la presencia de fitopatógenos sin necesidad de emplear productos químicos.
La distribución de estos microorganismos es afectada por la presencia de sustratos orgánicos, textura, temperatura, profundidad de los horizontes, pH y contenido de humedad, por lo que en las zonas aledañas a las raíces se encuentran en mayor abundancia (Ferrera-Cerrato, 2007). En complemento, los hongos anteriormente identificados por su hábito comúnmente saprofi- 
Tabla 3. Presencia $(+)$ y ausencia (-) de especies de hongos caracterizadas en los diferentes tratamientos en el muestreo 2.

\begin{tabular}{|l|c|c|c|c|c|}
\hline \multirow{2}{*}{ Género } & \multicolumn{5}{|c|}{ Tratamiento } \\
\cline { 2 - 6 } & Suelo & CA 100\% & CA 65\% FC 35\% & CA 35\% FC 65\% & FC 100\% \\
\hline Cladosporium sp. & $+(f=40,0 \%)$ & $+(f=42,9 \%)$ & $+(f=54,4 \%)$ & $+(f=75,5 \%)$ & $+(f=62,8 \%)$ \\
\hline Mucor sp. & $+(f=30,9 \%)$ & $+(f=50,4 \%)$ & $+(f=14,0 \%)$ & $+(f=9,4 \%)$ & $+(f=31,9 \%)$ \\
\hline Penicillium sp. & - & - & $+(f=25,0 \%)$ & $+(f=1,6 \%)$ & $+(f=1,1 \%)$ \\
\hline Trichoderma sp. & $+(f=1,8 \%)$ & - & - & - & \\
\hline Sin definir septado hialino & $+(f=27,3 \%)$ & $+(f=6,7 \%)$ & $+(f=6,6 \%)$ & $+(f=13,5 \%)$ & $+(f=4,2 \%)$ \\
\hline
\end{tabular}

$\mathrm{f}=$ porcentaje de ocurrencia a las 120 hds.

CA, Cascarilla de arroz; FC, fibra de coco.

to en el suelo pueden ser eficaces transformadores de sustratos edáficos en tejidos microbianos; algunos pueden asimilar entre el $30 \%$ y el $50 \%$ del carbono presente en la materia orgánica que descomponen, lo que representa una tasa de conversión muy superior a las bacterias, que se sitúa solamente entre el 5\% y el 20\% (Wild, 1989).

\section{Caracterización de las bacterias}

La cantidad y el tipo de bacterias están determinados por su contenido de arcilla, humedad, aireación, temperatura, contenido de materia orgánica y pH, así como por cultivo, estación del año, profundidad, abundancia de protozoarios y otros alimentos que se nutren de ellas (Ferrera-Cerrato, 2007). Las primeras bacterias caracterizadas en el muestreo 1 resultaron ser en su mayoría macroscópicamente de color amarillo (tabla 4) y microscópicamente cocos (tabla 5). Caso contrario en el muestreo 2 , en el cual la población de bacilos fue relativamente mayor y macroscópicamente su aspecto variaba de color amarillo a blancuzco.

Este cambio evidencia que la dinámica en la población de bacterias en el cultivo de rosas varia en cuanto a las formas, de coco a bacilos y quizás en visceversa, teniendo como variable de cambio el tiempo. En un contexto mayor, estos resultados van con la idea de que la mayoría de las bacterias del suelo son gram-negativas (Ferrera-Cerrato, 2007).
La observación directa de la flora bacteriana edáfica enseña que en casi todos los suelos predominan los cocos pequeños y bacilos cortos. La determinación inicial del comportamiento de bacterias gram + o gram-durante un tiempo de evaluación (un mes), permite tener una idea sobre la dinámica poblacional de las bacterias y nos permite inferir que tanto el ambiente como el sustrato van a estar sujetos a cambios de orden climático, químico o mecánico, los cuales van a afectar en definitiva la población bacteriana, desde el número hasta la diversidad.

\section{CONCLUSIONES}

El estudio de la dinámica poblacional permitió conocer que, teniendo como variable el tiempo, la población tanto de bacterias como de hongos puede fluctuar, en este caso aumentar, debido seguramente a condición favorable para el crecimiento y desarrollo de uno o varios géneros en el espacio.

Un porcentaje de ocurrencia relativamente alto por parte de los géneros Mucor y Cladosporium presente en todos los sustratos permite establecer una alta competencia y alta participación de estos en los procesos de formación del suelo. Asimismo, una posible interacción entre el género Mucor y Phytium, indicando la capacidad del primero de poder suprimir la actividad del segundo, 
Tabla 4. Caracterización macroscópica y microscópica de los morfotipos de bacterias con mayor frecuencia en sustratos de rosa en materas con recirculación de nutrientes para dos muestreos en Mosquera, Colombia.

\begin{tabular}{|c|c|c|c|c|c|c|c|c|c|c|c|c|}
\hline \multirow{2}{*}{ Muestreo } & \multirow{2}{*}{ Tratamiento } & \multirow{2}{*}{ Morfotipo } & \multicolumn{8}{|c|}{ Caracterización macroscópica } & \multicolumn{2}{|c|}{$\begin{array}{c}\text { Caracterización } \\
\text { microscópica }\end{array}$} \\
\hline & & & Color & Forma & Bordes & Tamaño & Superficie & Aspecto & Elevación & Consistencia & Forma & Tinción \\
\hline \multirow{7}{*}{1} & Suelo & $1 \mathrm{~A}$ & Blanca & Irregular & Ondulado & Grande & Rugosa & Brillante & Plana & Cerosa & Bacilo & Gram- \\
\hline & \multirow{2}{*}{ CA $100 \%$} & $2 \mathrm{~A}$ & Amarilla verde & Circular & Entero & Grande & Lisa & Mucosa & Plana & Cerosa & Coco & Gram+ \\
\hline & & $2 B$ & Amarilla pálida & Circular & Entero & Grande & Lisa & Brillante & Umbonada & Cerosa & Coco & Gram+ \\
\hline & CA $65 \%$ FC $35 \%$ & $3 \mathrm{~A}$ & Amarilla verde & Circular & Entero & Grande & Lisa & Mucosa & Convexa & Cerosa & Diploco & Gram- \\
\hline & CA $35 \%$ FC $65 \%$ & $4 \mathrm{~A}$ & Amarillo ocre & Circular & Entero & Mediana & Lisa & Opaca & Convexa & Cerosa & Diploco & Gram- \\
\hline & \multirow{2}{*}{ FC 100\% } & $5 A$ & Café claro & Irregular & Entero & Grande & Lisa & Brillante & Plana & Cerosa & Coco & Gram- \\
\hline & & $5 B$ & Blanco-crema & Irregular & Entero & Mediana & Lisa & Brillante & Convexa & Cerosa & Coco & Gram+ \\
\hline \multirow{11}{*}{2} & \multirow{2}{*}{ Suelo } & $6 \mathrm{~A}$ & Amarillo claro & Circular & Entero & Mediana & Lisa & Brillante & Convexa & Cerosa & Bacilo & Gram- \\
\hline & & $6 \mathrm{~B}$ & Blanco & Circular & Entero & Grande & Lisa & Seca, ораса & Plana & Cerosa & Coco & Gram- \\
\hline & \multirow{2}{*}{ CA $100 \%$} & $7 \mathrm{~A}$ & Amarillo verdoso & Circular & Entero & Mediana & Lisa & Brillante & Convexa & Cerosa & Coco & Gram- \\
\hline & & $7 \mathrm{~B}$ & Blanco & Circular & Entero & Mediana & Lisa & Brillante & Convexa & Cerosa & Bacilo & Gram- \\
\hline & \multirow{2}{*}{ CA 65\% FC 35\% } & $8 \mathrm{~A}$ & Amarillo verdoso & Circular & Entero & Mediana & Lisa & Brillante & Convexa & Cerosa & Bacilo & Gram- \\
\hline & & $8 \mathrm{~B}$ & Blanco & Circular & Entero & Grande & Lisa & Brillante & Convexa & Cerosa & Bacilo & Gram- \\
\hline & \multirow{2}{*}{ CA 35\% FC 65\% } & $9 \mathrm{~A}$ & Amarillo naranja & Circular & Entero & Mediana & Lisa & Brillante & Umbonada & Cerosa & Bacilo & Gram- \\
\hline & & $9 \mathrm{~B}$ & Blanco & Circular & Entero & Mediana & Lisa & Brillante & Convexa & Cerosa & Bacilo & Gram- \\
\hline & \multirow{3}{*}{ FC 100\% } & $10 \mathrm{~A}$ & Amarillo quemado & Circular & Entero & Mediana & Lisa & Brillante & Convexa & Cerosa & Bacilo & Gram+ \\
\hline & & $10 \mathrm{~B}$ & Amarillo verdoso & Circular & Entero & Mediana & Lisa & Brillante & Convexa & Cerosa & Coco & Gram- \\
\hline & & $10 \mathrm{C}$ & Blanco & Irregular & Ondulado & Grande & Rugosa & Seca & Umbonada & Cerosa & Diploco & Gram- \\
\hline
\end{tabular}


Tabla 5. Cantidad de bacterias con mayor frecuencia presentes en cada uno de los muestreos teniendo en cuenta todos los tratamientos.

\begin{tabular}{|c|c|c|c|c|}
\hline \multirow{2}{*}{ Muestre0 } & \multicolumn{4}{|c|}{$\begin{array}{c}\text { Número de bacterias presentes } \\
\text { según su forma }\end{array}$} \\
\cline { 2 - 5 } & $\begin{array}{c}\text { Coco } \\
\text { Gram+ }\end{array}$ & $\begin{array}{c}\text { Coco } \\
\text { Gram- }\end{array}$ & $\begin{array}{c}\text { Bacilo } \\
\text { Gram+ }\end{array}$ & $\begin{array}{c}\text { Bacilo } \\
\text { Gram- }\end{array}$ \\
\hline 1 & 3 & 3 & 0 & 1 \\
\hline 2 & 0 & 4 & 1 & 6 \\
\hline
\end{tabular}

y de esta forma la presencia de Phytium, sólo se pudo ver expresada en las cajas de Petri en ausencia de colonias de Mucor.

Aunque la identificación de bacterias no se realizó, la caracterización y uso de tinción de gram permitió observar diferencias claras en cuanto a presencia y ausencia de diferentes formas (cocos o bacilos) bacterianas de acuerdo con el tiempo de muestreo. Esto permite establecer al tiempo como una variable indirecta en la cual se percibe un cambio en cuanto a la diversidad y frecuencia sin excluir que está directamente influido por condiciones climáticas, físico-químicas del sustrato y manejo del cultivo.

Con fines fitopatológicos, se recomienda detallar con mayor profundidad la especie perteneciente a los géneros de hongos encontrados e identificar las bacterias que en el ensayo se marcaron como bacilos y en mayor medida las gram negativa, ya que son las que mayor daño pueden generar al cultivo de rosa. Si es posible, con el ámbito de entender con un nivel más preciso y mejor la diversidad microbial del suelo el estudio se vería muy enriquecido con introducción de técnicas moleculares.

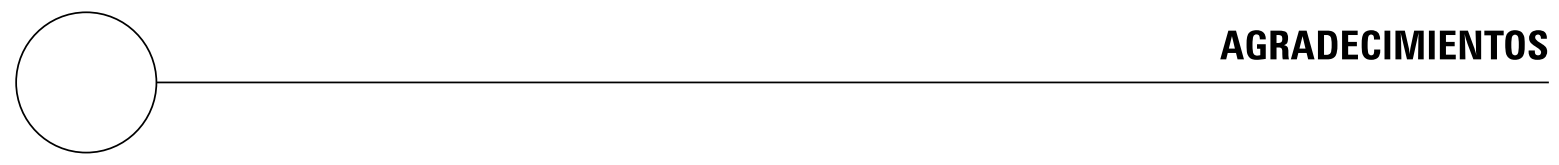

Los autores agradecen a la Universidad Nacional de Colombia y al personal de invernaderos del proyecto "Producción más limpia de rosa y clavel con dos técnicas de cultivo sin suelo en la Sabana de Bogotá" y laboratorios, así como a los profesores Víctor Flórez y Diego Nieto por su colaboración en la realización y análisis del presente estudio. 


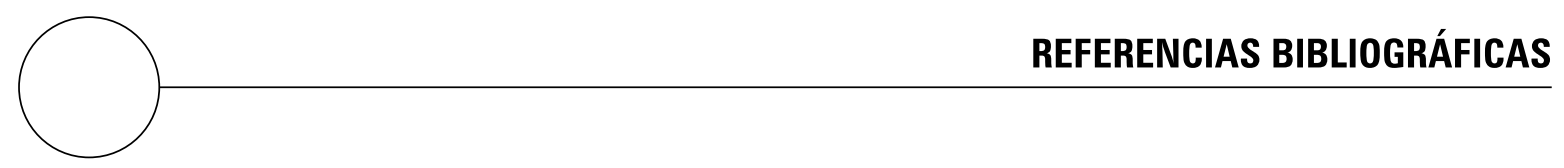

Agrios, G. 2005. Plant pathology. $5^{\text {th }}$ ed. Elsevier Academic Press, New York, NY.

Asocolflores. 2003. Asociación Colombiana de Exportadores de Flores. Boletín 176, Bogotá.

Asocolflores. 2007. Estadísticas 2007: Floricultura Colombiana. En: Asocolflores, http://www.asocolflores.org/asocolflores/servlet/Download?.idExter nalFile $=236 \&$ name $=$ HOJA-DATOS-2008-7.pdf. 4 p.; consulta: mayo de 2008.

Barnett, H.L. y B.B. Hunter. 1998. Illustrated genera of imperfect fungi. $4^{\text {th }}$ ed. American Phytopathological Society, New York, NY.

Blaine, F. 1992. Soil microbial ecology: applications in agricultural and environmental management. Marcel Dekker, New York, NY.

Bergey, D.H. 1984. Bergey's manual of systematic bacteriology. Williams and Wilkins, Baltimore, $\mathrm{MD}$.

Buyer, J.S.; D.P. Roberts y E. Russek-Cohen. 1999. Microbial community structure and function in the spermosphere as affected by soil and seed type. Can. J. Microbiol. 48(11), 955-964.

Cattelan, A.J.; P.G. Hartel y J.J. Fuhrmann. 1998. Bacterial composition in the rhizosphere of nodulating and non-nodulating soybean. Soil Sci. Soc. Amer. J. 62(6), 1549-1555.

Chave, M., P. Dabert, R. Brun, J.J. Godon y C. Poncet. 2008. Dynamics of rhizoplane bacterial communities subjected to physicochemical treatments in hydroponic crops. Crop Prot. 27(3), 418-426.

Damastri, C.; L. Chiarini; C. Cantale; A. Bevivno y S. Tabacchioni. 1999. Soil type and maize cultivar affect the genetic diversity of maize-associated Burkholderia cepacia populations. Microb. Ecol. 38(3), 273-284.

Dubey, S.K.; A.K. Tripathi y S.N. Upadhyay. 2006. Exploration of soil bacterial communities for their potential as bioresource. Biores. Technol. 97(17), 2217-2224.
Ezziyyani, M.; C. Pérez; A.S. Ahmed; M.E. Requena y M.E. Candela. Trichoderma harzianum como biofungicida para el biocontrol de Phytophthora capsici en plantas de pimiento (Capsicum annuum L.). Anales de Biología 26(1), 35-45.

Fernández-Larrea, O. 2001. Microorganismos antagonistas para el control fitosanitario. Man. Integr. Plag. 62(2), 96-100.

Ferrera-Cerrato, R. 2007. Microbiología agrícola. Trillas, México D.F.

Gomes, N.; O. Fagbola; R. Costa; N. Rumjanek; A. Buchner; L. Mendona-Hagler y K. Smalla. 2003. Dynamics of fungal communities in bulk and maize rhizosphere soil in the tropics. Appl. Environ. Microbiol. 69(7), 3758-3766.

Grayston, S.J.; S. Wang; C.D. Campbell y A.C. Edwards. 1998. Selective influence of plant species on microbial diversity in the rhizosphere. Soil Biol. Biochem. 30(3), 369-378.

Marschner, P.; C. Yang; R. Lieberei y D.E. Crowley. 2001. Soil and plant specific effects on bacterial community composition in the rhizosphere. Soil Biol. Biochem. 33(11), 1437-1445.

Miethling, R.; G. Wieland; H. Backhaus y C.C. Tebbe. 2000. Variation of microbial rhizosphere communities in response to crop species, soil origin, and inoculation with Sinorhizobium meliloti L33. Microb. Ecol. 40(1), 43-56.

Pizano, M. 2000. Clavel. Ediciones HortiTecnia, Bogotá.

Olalde, V. y L.I. Aguilera. 1998. Microorganismos y biodiversidad. Terra Latinoamericana 16(3), 289-292.

Steijl, H., G.J. Niemann y J.J. Boon. 1999. Changes in chemical composition related to fungal infection and induced resistance in carnation and radish investigated by pyrolysis mass spectrometry. Physiol. Mol. Plant Pathol. 55(5), 297-311.

Smith, I. 1992. Manual de enfermedades de las plantas. Ediciones Mundi-Prensa, Madrid.

Wild, A. 1989. Condiciones del sueloy desarrollo de las plantas según Russel. Ediciones Mundi-Prensa, Madrid. 